\title{
O TERRITÓRIO DO PROJETO GEOPARQUE CAMINHO DOS CÂNIONS DO SUL
}

\section{THE TERRITORY OF THE GEOPARK PROJECT CAMINHO DOS CÂNIONS DO SUL}

\section{Paola Magnus Carvalho \\ Graduada em Geografia pela Universidade do Extremo Sul Catarinense/UNESC paolamagnusc@gmail.com \\ José Gustavo Santos da Silva}

Laboratório de Planejamento e Gestão Territorial, Universidade do Extremo Sul Catarinense, Mestrando em Ciências Ambientais PPGCA/UNESC, gustasantos92@gmail.com

Bruno Netto da Silva

Graduado em Geografia pela Universidade do Extremo Sul Catarinense/UNESC Brunonetto87@gmail.com

\section{RESUMO}

Os Geoparques são áreas geográficas que contém locais e paisagens de importância geológica nacional e internacional. No ano de 2006, foi proposto o projeto Geoparque Caminho dos Cânions do Sul, tendo em vista a conservação e a preservação do patrimônio geológico, bens naturais e culturais que o território do projeto possui. Considerando que um dos objetivos dos Geoparques é o desenvolvimento de atividades de educação e divulgação das Geociências, o artigo tem como objetivo analisar como vem sendo desenvolvido o conceito do Geoparque Caminho dos Cânions do Sul, tomando como estudo de caso a escola Afonso Bedinot, no município de Mampituba/RS, com o intuito de investigar o conhecimento dos alunos acerca das Geociências, e também verificar a forma como os docentes vem trabalhando estas temáticas. Para o desenvolvimento deste trabalho, realizou-se uma pesquisa bibliográfica e documental. Posteriormente, foi realizado uma observação participante com o corpo docente e alunos. Constatouse, por meio do estudo realizado, que tanto os professores, como os alunos, possuem um conhecimento limitado sobre o projeto Geoparque, o que fortalece a necessidade desenvolver atividades no território do projeto Geoparque dentro do espaço escolar.

Palavras-chave: Geociências, Educação, Patrimônio Geológico.

\section{ABSTRACT}

Geoparks are geographical areas that contain sites and landscapes of national and international geological importance. In 2006, the Geopark Way of the Southern Canyons Project was proposed, with a view to the conservation and preservation of the geological heritage, natural and cultural assets that the project territory has. Considering that one of the objectives of the Geoparks is the development of Geosciences education and dissemination activities, the article aims to analyze how the concept of the Southern Canyons Road Geopark has been developed, taking as a case study the Afonso Bedinot School in the municipality of Mampituba / RS, in order to investigate students' knowledge about Geosciences, and also verify the way teachers have been working on these themes. For the development of this work, a bibliographical and documentary research was carried through. Subsequently, a participant observation was made with the faculty and students. It was found from the study that both teachers and students have limited knowledge about the Geopark project, which strengthens the need to develop activities in the territory of the Geopark project within the school space.

Keywords: Geosciences, Education, Geological Heritage. 


\section{INTRODUÇÃO}

As primeiras propostas de criação dos Geoparques tiveram origem na Europa, no ano de 2000. Apesar do conceito de Geoparque ainda ser pouco conhecido no Brasil, ele é uma importante estratégia para o desenvolvimento regional sustentável. Brilha (2009) aponta que um Geoparque é uma área onde se encontram estratégias de desenvolvimento baseadas na conservação do patrimônio geológico, natural e cultural com vista à melhoria das condições de vida das populações que o habitam.

Conforme apresentado pelo Serviço Geológico do Brasil, hoje existem 30 propostas de projetos de Geoparques e uma delas é o Geoparque Caminho dos Cânions do Sul, enfoque deste trabalho. Conforme Godoy, Binotto e Widner (2010), a área do projeto está localizada entre as divisas dos estados do Rio Grande do Sul e de Santa Catarina e abrange sete municípios distribuídos em uma área total de $2.830 \mathrm{~km}^{2}$. Ainda, segundo os autores, a região cumpre os pré-requisitos básicos estabelecidos pela Organização das Nações Unidas para a Educação, a Ciência e a Cultura (UNESCO), apresentando uma área de tamanho considerável, relevância de sítios geológicos e geomorfológicos, infraestrutura para o turismo e uma identidade cultural local.

A geoeducação é um dos pilares do Geoparque, da qual se busca desenvolver programas de educação, pesquisa científica e divulgação das Geociências, e assim este aspecto se mostra fundamental. "Sem a base educacional não é possível uma interação entre desenvolvimento econômico e cultural e a conservação do ambiente necessária na criação de um geoparque” (BACCI et al., 2009, p. 12).

A divulgação destes conceitos ao público estudantil é muito importante. Fé (2015), destaca que essa importância se dá pelo fato dos estudantes serem mais abertos a esse tipo de iniciativa e dos mesmos terem sua criticidade mais acentuada. Desta forma, no ambiente escolar, é possível, por meio de uma boa gestão, e de qualificação dos professores, integrar os conteúdos pertinentes dentro do Geoparque com os conteúdos curriculares da escola. Além de poderem ser trabalhados de forma interdisciplinar.

Pode-se notar que os currículos propostos dentro da grade educacional do ensino fundamental e médio no Brasil "não contemplam satisfatoriamente os conceitos geocientíficos na formação dos indivíduos, o que pode explicar a grande dificuldade dos cidadãos para compreensão do funcionamento do Planeta." (BACCI et al., 2009, p. 12 apud CARNEIRO et al., 2004). "Essa falta de informação reflete-se diretamente na baixa valorização do patrimônio geológico e cultural do país e nas depredações de forma geral” (BACCI et al., 2009, p. 12 apud REYS et al., 2007).

As ações geradas entre os Geoparques e a educação originam, de acordo com Bacci et al., (2009) um impulso do processo educacional e permitem difundir o conhecimento científico junto à 
sociedade. Os alunos passam a ser atores sociais desse meio, e passam a "compreender e interpretar o ambiente natural” (RODRIGUES; CARVALHO; CATANA, 2013, p. 4).

Em vista das poucas pesquisas realizadas sobre o território do projeto do Geoparque Caminho dos Cânions no eixo educação, percebeu-se a necessidade de trabalhar está temática dentro de uma das escolas pertencentes ao projeto.

Para se tentar suprir parte destas deficiências, o presente trabalho propõe analisar como vem sendo desenvolvido o conceito do Geoparque Caminho dos Cânions do Sul, tomando como estudo de caso a escola Afonso Bedinot, no município de Mampituba/RS, com o intuito de investigar o conhecimento dos alunos acerca das Geociências, e também verificar a forma como os docentes vem trabalhando estas temáticas.

\section{GEOPARQUES}

A UNESCO (2010), define um Geoparque como uma área com seus limites bem definidos, apresentando locais com importância internacional, regional e/ou local que contenha uma diversidade geológica, geomorfológica, ecológica e valor arqueológico, histórico e cultural. Um Geoparque está sustentado sob três pilares: geodiversidade, geoeducação e geoturismo.

\section{Figura 1 - Pilares Geoparque}

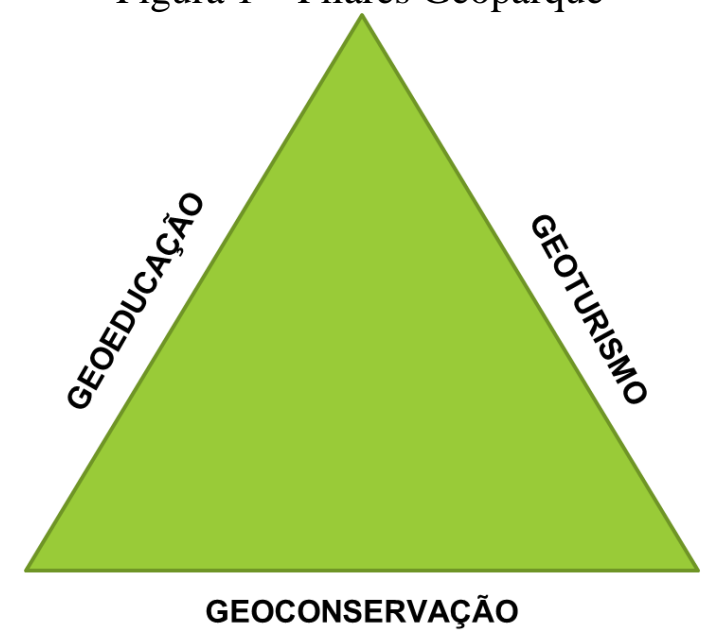

Fonte: Os autores (2019)

A abundância dentro dos Geoparques, desde suas rochas, minerais, fósseis, vegetação e solos, consiste, de acordo com Brilha (2005), no conceito de geodiversidades. As práticas voltadas para a conservação das geodiversidades são intituladas de geoconservação.

A UNESCO (2010), aponta que um dos objetivos do Geoparque é estimular a atividade econômica e o desenvolvimento sustentável a partir de um novo segmento de turismo, o geoturismo. De acordo com Arouca (2011), o geoturismo é compreendido como o turismo que sustenta e incrementa a identidade de um território, considerando a sua geologia, ambiente, cultura, valores 
estéticos, patrimônio e o bem-estar de seus residentes. Este segmento assume grande importância dentro de um Geoparque, pois é possível buscar a conservação e sustentabilidade local.

Toda esta diversidade deve fazer parte de um conceito de proteção e desenvolvimento sustentável, que será promovido através da geoeducação, pelos estudos das geociências e educação ambiental.

As geodiversidades presentes dentro destes territórios podem ser reconhecidas e se tornarem um geossítio. Brilha considera que um geossítio é:

A ocorrência de um ou mais elementos da Geodiversidades (aflorantes quer em resultado da ação de processos naturais quer devido à intervenção humana), bem delimitado geograficamente e que apresente valor singular do ponto de vista científico, pedagógico, cultural, turístico ou outro (BRILHA, 2005, p. 5).

De acordo com Rosa et al. (2015), a proposta de um projeto de Geoparque deve ser construída e submetida ao Programa Geoturismo da Companhia de Pesquisa de Recursos Minerais (CPRM). No Brasil, o único Geoparque consolidado é o Geoparque Araripe, localizado no estado do Ceará.

\section{DO GEOPARQUE A CONCEPÇÃO DE LUGAR}

Sendo que a Geografia tem como enfoque de estudo o espaço geográfico e as relações do homem com esse meio, ela sempre estará presente nas discussões de gestão territorial.

Busca-se, com a implementação dos geoparques, que a população do seu entorno crie associações com esses locais, para permitir o seu desenvolvimento. A criação de um sentimento de pertencimento, convivência, afetividade e valorização dos estudantes aos geoparques, permite com que seja feita uma correlação do mesmo ao conceito de lugar, ou seja, nesta pequena porção do espaço geográfico vão sendo desenvolvidas atividades que levam a criação de uma identidade.

Santos (1994, p. 6), define o lugar como "ponto de encontro de interesses longínquos e próximos, mundiais e locais, manifestados segundo uma gama de classificações que está se ampliando e mudando". Estas mudanças, correspondem as mudanças humanas, que o reorganiza a partir de suas necessidades, criando um sentimento de pertencimento, até poder chamá-lo de lugar.

Ainda de acordo com o autor "cada lugar, não importa onde se encontre, revela o mundo (no que ele é, mas também naquilo que ele não é), já que todos os lugares são suscetíveis de intercomunicação" (1994, p. 20). O espaço e o lugar vão sempre estar em sintonia, construindo uma rede de conexões socioespaciais.

Santos ainda interpreta o lugar como "condição e suporte das relações globais" (SANTOS, 2005, p. 156), assim cada lugar, a partir de sua estrutura, se correlacionam com o mundo globalizado. 
Oliveira (2014) aponta que o reconhecimento da cultura e de pertencimento aos locais e a elaboração de ações no engajamento da população em torno de seus "lugares", geram o empoderamento da comunidade sobre o território dos Geoparques, gerando o crescimento do mesmo.

\section{METODOLOGIA}

O Projeto Geoparque Caminho dos Cânions do Sul é integrado por três municípios do estado do Rio Grande do Sul - Cambará do Sul, Mampituba e Torres -, e por quatro municípios no estado de Santa Catarina - Jacinto Machado, Morro Grande, Praia Grande e Timbé do Sul -, como pode ser observado na figura 2.

Figura 2 - Localização do território do Projeto Geoparque

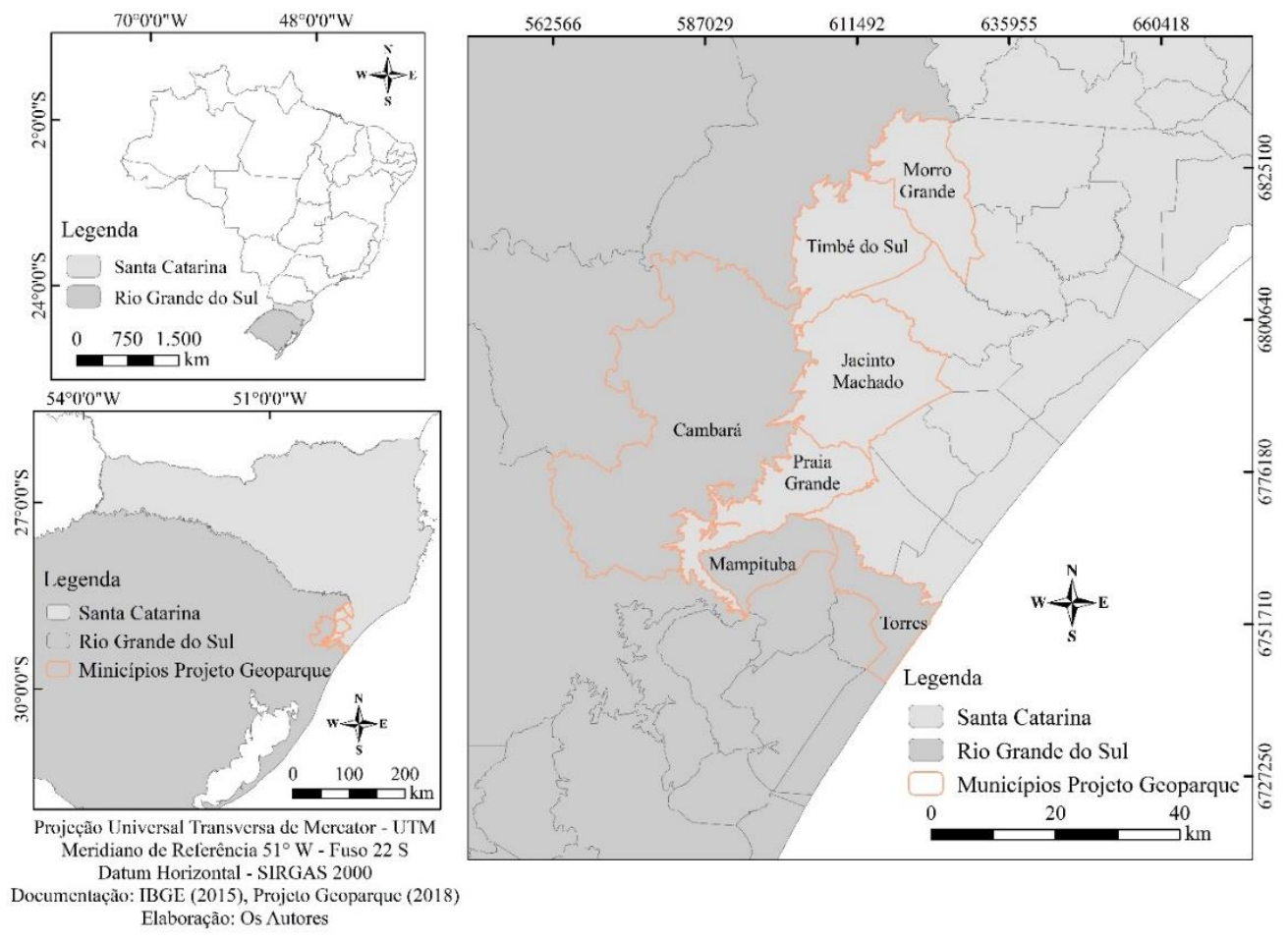

Fonte: Os autores (2019)

Este território abrange uma área de $2.830 \mathrm{~km}^{2}$ e contempla uma população total de 70.049 habitantes. Na tabela 1, pode-se observar o número total de habitantes dos municípios integrantes do projeto, tanto no meio rural, quanto no meio urbano.

Tabela 1 - População total dos municípios integrantes do projeto Geoparque

\begin{tabular}{cccc}
\hline Município & População Urbana & População Rural & Total \\
\hline Cambará do Sul & 3.041 & 3.501 & 6.542 \\
Jacinto Machado & 5.113 & 5.476 & 10.589 \\
\hline
\end{tabular}




\begin{tabular}{cccc}
\hline Mampituba & 568 & 2.435 & 3.003 \\
Morro Grande & 756 & 2.131 & 2.887 \\
Praia Grande & 4.297 & 2.970 & 7.267 \\
Timbé do Sul & 1.845 & 3.463 & 5.308 \\
Torres & 33.340 & 1.113 & 34.453 \\
Total & 48.960 & 21.089 & 70.049 \\
\hline
\end{tabular}

Fonte: Fonte: PNUD, Ipea, FJP (2013).

Nota-se, que em quase todos os municípios a população rural é predominante, exceto no município de Torres - RS, cuja população urbana é tão numerosa que faz com que o total da população urbana nos municípios integrantes do projeto Geoparque seja maior que o total da população rural.

A área que o projeto incorpora possui uma grande diversidade de sítios geológicos e geomorfológicos, está inserida dentro do Bioma Mata Atlântica e apresenta predominância do clima subtropical. Todos estes aspectos físicos naturais contribuíram para os processos de ocupação da região permitindo a construção de um patrimônio cultural.

O desenvolvimento do trabalho, ocorreu na Escola Municipal de Ensino Fundamental Afonso Bedinot, localizada no município de Mampituba/RS, território integrante do projeto Geoparque Caminho dos Cânions do Sul. A pesquisa foi realizada nas turmas de $6^{\circ}$ e $9^{\circ}$ ano. Também foram observados os procedimentos de aprendizagem utilizados pelos professores, assim como o domínio de conhecimento acerca do tema. Na tabela 2 é possível observar a quantidade de alunos que participaram do desenvolvimento da pesquisa.

Tabela 2 - Número de alunos por turma

\begin{tabular}{ll}
\hline Turma & Número de alunos \\
\hline $6^{\circ}$ ano & 19 \\
$9^{\circ}$ ano & 28 \\
\hline
\end{tabular}

Fonte: Os autores, 2019

A pesquisa caracteriza-se como um estudo de caso. De acordo com Yin (2001), o estudo de caso possibilita investigar um fenômeno dentro de seu contexto da vida real por meio de uma investigação empírica.

A produção do referencial teórico deste trabalho envolveu a pesquisa bibliográfica de artigos relacionados ao tema sobre Geoparque e sua relação na educação e ao conceito de lugar.

A pesquisa teve como embasamento documentos da UNESCO (2010), e nos trabalhos de Brilha (2005), Rosa et al. (2015) e Tomasi (2011). 
Autores como Fé et. al. (2016), Brilha (2009) e Rodrigues (2013), foram utilizados para registrar no trabalho a importância dos Geoparques na Educação. Quando argumentado a relação ao conceito de lugar, a pesquisa se fundamentou em Santos (1994), Oliveira (2014) e Gonçalves (2013).

A pesquisa se apoia também nas informações disponibilizadas no site da Prefeitura Municipal de Mampituba e do Geoparque Caminho dos Cânions do Sul, e também no Projeto Político Pedagógico da escola.

Concomitantemente a pesquisa bibliográfica foi realizada a observação participante para a coleta de dados, nas turmas de $6^{\circ}$ e $9^{\circ}$, já mencionadas. A observação participante consiste em "um tipo especial de observação, na qual o observador deixa de ser um membro passivo e pode assumir vários papéis na situação do caso em estudo [...]”' (CAVALCANTI, MOREIRA, 2007, p. 73). Usando este tipo de coleta de dados, é possível "perceber a realidade do ponto de vista de alguém de "dentro" do estudo de caso, e não de um ponto de vista externo.” (YIN, 2001, p. 116). Desta forma, é viável articular a teoria e prática durante toda a coleta dos dados para a pesquisa, pois o investigador estará se inserindo no ambiente natural do grupo pesquisado.

\section{RESULTADOS E DISCUSSÕES}

O primeiro item a ser levado em consideração, seria verificar se alunos e professores conheciam o projeto Geoparque. Durante as observações era visível que todos os professores já o conheciam, mas quando analisado o conhecimento dos alunos, um número expressivo não tinha conhecimento sobre, ainda que a temática já tivesse sido trabalhada na escola. A partir desta análise, foi possível construir um panorama entre as duas turmas, como pode ser observado na tabela 3.

Tabela 3 - Número de alunos que conhecem o Projeto Geoparque.

\begin{tabular}{cccc}
\hline Turmas & $\begin{array}{c}\text { Número de alunos } \\
\text { que conhecem o } \\
\text { projeto }\end{array}$ & $\begin{array}{c}\text { Número de alunos } \\
\text { que não conhecem o } \\
\text { projeto }\end{array}$ & Total \\
\hline $6^{\circ}$ ano & 17 & 2 & 19 \\
$9^{\circ}$ ano & 24 & 4 & 28 \\
Total & 41 & 6 & 47 \\
\hline
\end{tabular}

Fonte: Os autores (2019)

Apesar da maioria dos alunos conhecerem o projeto, observou-se que o grau de conhecimento era regular, pois muitos demonstraram desconhecimento sobre temáticas voltadas para as geociências e a educação ambiental.

A maior dificuldade dos alunos foi conceituar um geossítio e identifica-lo no município de Mampituba. Percebe-se que há dificuldade por parte dos alunos para definirem este conceito, assim como dos professores em estarem trabalhando temáticas relacionadas ao mesmo. 
Os únicos geossítios existentes dentro do município é o Santuário de Nossa Senhora Aparecida e a Cachoeira dos Borges e que não foi citado pela maioria dos alunos durante as discussões. Vale ressaltar ainda, que durante o estudo, alguns alunos destacam o Itaimbezinho e o Malacara, que são geossítios, mas que não pertencem ao município de Mampituba, e sim de Cambará do Sul e Praia Grande, respectivamente. Isto demostra que os alunos possuem dificuldade para estar se localizando dentro do espaço geográfico

Durante o desenvolvimento de projetos como este no espaço escolar, é de extrema importância aliar a teoria e prática, pois conforme Brilha (2009), estas ações levam a promoção da multidisciplinaridade, onde são integrados a geodiversidade, biodiversidade e cultura. A realização de saídas a campo também é um instrumento fundamental para a criação de um sentimento de pertencimento por parte dos alunos com estes locais.

Para isto, saídas a campo seriam fundamentais para a apropriação do conhecimento sobre as geociências e educação ambiental. Durante a observação notou-se que a maioria dos alunos do $6^{\circ}$ ano não haviam realizado saídas a campo de estudo dentro do território do projeto Geoparque. Já na turma do $9^{\circ}$ ano, o número de alunos que realizaram um estudo fora da sala de aula, foi maior.

Outro ponto que deve ser levantado, é de que muitos alunos não têm conhecimento do por que o município de Mampituba está inserido dentro do território do projeto do Geoparque. Durante a observação dos trabalhos que foram feitos pelos professores, foi possível fazer um levantamento dos seguintes dados, que são apresentados no gráfico 4.

Tabela 4 - Percentual de alunos que compreendem porque o município está inserido dentro do Geoparque

\begin{tabular}{cccc}
\hline Turmas & $\begin{array}{c}\text { Número de alunos } \\
\text { que compreendem }\end{array}$ & $\begin{array}{c}\text { Número de alunos } \\
\text { que não } \\
\text { compreendem }\end{array}$ & Total \\
\hline $6^{\circ}$ ano & 9 & 10 & 19 \\
$9^{\circ}$ ano & 18 & 10 & 28 \\
Total & 27 & 20 & 47 \\
\hline
\end{tabular}

Fonte: Os autores (2019)

Nas duas turmas, os alunos evidenciaram a questão das belezas naturais do município, como sendo o principal motivo observado. Muitos também apontaram a questão dos pontos turísticos, assim como citaram a preservação da natureza e melhorias para o município. Estes dois últimos, salientam que os alunos possuem um conhecimento muito restrito, pois fazem a confusão entre os motivos que levam Mampituba a ser integrante do projeto, com os benefícios trazidos pelo mesmo.

Dentro deste ponto, existem várias outras questões que devem ser levadas em consideração, das quais os professores possuem dificuldades em abordar. O município possui sítios geológicos e 
geomorfológicos relevantes, já que sua área fez parte de uma antiga província ígnea e do deserto de Botucatú. Também está inserido dentro do Bioma Mata Atlântica, possui um histórico cultural presente e já possui infraestrutura para o turismo rural. Todos estes aspectos influenciam na inserção do município dentro da proposta.

O mesmo ocorre quando estudado sobre os benefícios que o projeto trará ao município. Nas duas turmas, os alunos limitam este benefício somente ao turismo, mas outros aspectos devem ser levados em consideração, como os benefícios a conservação do patrimônio geológico, promoção da pesquisa científica, desenvolvimento de programas de educação e promoção das geociências, valorização do patrimônio cultural e natural, aumento da demanda por produtos locais e crescimento da identidade com o território, o que leva ao favorecimento dos níveis social, econômico, cultural, educacional, ecológico e científico, e este conjunto permite o desenvolvimento e crescimento sustentável do município.

Quando observado a diligência do corpo docente acerca das questões voltadas ao território do projeto Geoparque, nota-se, que mesmo todos os professores conhecendo a proposta, a maioria apresenta ainda muita dificuldade de realizar os trabalhos referentes à educação ambiental e às geociências, que são de extrema importância dentro do contexto de um Geoparque. Além disso, a maior dificuldade do corpo docente é trabalhar de forma interdisciplinar estas questões.

Isto se evidenciou cada vez mais nas observações, quando apenas uma professora estava conseguindo fazer uma correlação com o conteúdo, ocasionando o envolvimento maior por parte da mesma, dentro do projeto Geoparque Caminho dos Cânions.

Em função disso, a professora já promoveu saídas a campo com os alunos, estudo dos solos e das rochas de Mampituba, estudo de fotos das comunidades de Mampituba e desenvolvimento de atividades no dia da Terra. Os alunos de toda a escola, também receberam mudas de árvores frutíferas e nativas doadas pela equipe do projeto.

É importante ressaltar, que na escola o professor habilitado na área de História, além de atuar em sua área de conhecimento, preenche sua carga horária atuando na disciplina de Geografia.

Todo o grupo escolar da escola Afonso Bedinot vem participando de palestras/cursos/formações desde 2018. Durante este período os professores participaram de uma palestra voltada para a temática de Geologia, e neste ano já foram realizadas formações voltada para a temática de Paleontologia - promovida pela Universidade do Contestado, e de Arqueologia promovida pela Universidade do Extremo Sul Catarinense. Foi realizado também um tour pelo município para conhecer os pontos turísticos de Mampituba. E no final do ano de 2018, foi realizado uma mostra de trabalhos na escola cujo tema era "Geoparque". 
Nas observações realizadas, percebe-se a falta de recursos materiais que a escola possui e organizar as saídas à campo, decorrente de falta de investimentos externos, o que acaba desestimulando os professores. Há também dificuldade de fazer a ligação deste projeto com outras áreas do conhecimento.

\section{CONSIDERAÇÕES FINAIS}

Evidenciou-se que o Projeto Geoparque Caminhos dos Cânions se estabeleceu na escola Afonso Bedinot no ano de 2018, após o encontro com representantes do projeto. Em função disto, o tempo para consolidação de projetos e atividades ainda é curto.

A geoeducação, um dos pilares do Geoparque, propõe que estas atividades sejam desenvolvidas de forma interdisciplinar nas escolas. Nota-se que isto não vem ocorrendo. Percebe-se que todo o grupo escolar tem dificuldade em realizar a interligação do seu conteúdo com o projeto, e de estar trabalhando isso com outras disciplinas.

$\mathrm{Na}$ análise do Projeto Político Pedagógico, a escola não apresenta nenhuma informação referente ao território do projeto Geoparque Caminho dos Cânions. Quando abordado a questão de projetos em geral, o documento traz apenas a informação de que as iniciativas dos professores para desenvolver projetos de atividades (interdisciplinares) em sala de aula deverão ser encaminhadas na modalidade "Projeto de ensino" para a direção e após análise e concordância será viabilizado.

Os resultados mostram, que o conhecimento dos alunos sobre o projeto ainda encontra-se de forma fragmentada, necessitando investimentos. Em função disto, os alunos ainda não conseguiram criar um sentimento de afetividade com este território, e em função disto não o identifica como lugar.

Conclui-se que há necessidade do projeto Geoparque Caminho dos Cânions trazer formação para este grupo docente, para que os mesmos estejam inteirados e tenham o conhecimento necessário para desenvolverem atividades com os alunos. Pois, como constatou-se o conhecimento sobre educação ambiental e geociências ainda está em processo de construção.

Os estudos das geociências e da educação ambiental auxiliam os alunos a entenderem melhor o objetivo do Projeto Geoparque Caminho dos Cânions do Sul, compreendendo os motivos que levam o seu município a se inserir dentro da proposta. A fim de difundir o conhecimento, capacitações voltadas para o estudo do patrimônio geológico local, se mostram fundamentais. A partir deste aprofundamento, tanto por parte de professores e alunos, é possível realizar trabalhos voltados ao reconhecimento das rochas, a partir de saídas a campo, e estar construindo na escola um acervo de rochas e minerais encontrados no município. O estudo do patrimônio geológico local também permitirá que os alunos identifiquem e caracterizem um geossítio dentro de seu município. 
O conhecimento da educação ambiental também deve ser fortalecido na escola. Wokshops voltados para os trabalhos relacionados à temática de resíduos sólidos contribuem para o desenvolvimento do pilar da geoconservação. Visando a mudança de hábitos dos alunos, os professores podem estar desenvolvendo oficinas de reutilização de materiais recicláveis e mutirões de limpeza em locais específicos do território.

Além dessas, outras atividades podem ser desenvolvidas dentro do espaço escolar com os alunos, abrangendo outros campos de estudos, como a paleontologia, arqueologia e geomorfologia. Podem ser realizados oficinas de réplicas de fósseis, confecção de maquetes representando o relevo do município, neste caso, pode-se novamente trazer o enfoque do geossítio, oficinas de escavação, cerâmica, e de lascamento.

Para o fortalecimento da identidade cultural local, a escola pode desenvolver eventos com apresentações dos alunos, e exposição de culinária e artesanato local.

Estes estudos abrangendo a área das geociências e da educação ambiental auxiliam o corpo docente da escola e estudantes, a compreender aspectos relevantes e que norteiam o projeto. A formação dos professores, contribuirá para a ampliação do conhecimento dos alunos sobre, promovendo em cada um deles a criação de uma identidade com o território.

\section{REFERÊNCIAS}

AROUCA GEOPARK (Portugal). O Congresso Internacional de Geoturismo - "Geotourism in Action - Arouca 2011”, Portugal, 9 a 13 de novembro de 2011.

BACCI, Denise de La Corte et al. Geoparque: Estratégia de Geoconservação e Projetos Educacionais. Geologia Usp, São Paulo, v. 5, n. 1, p.7-15, out. 2009.

BRASIL. LEI FEDERAL N N $^{\circ} .795$, DE 27 DE ABRIL DE 1999. Dispõe sobre a educação ambiental, institui a Política Nacional de Educação Ambiental e dá outras providências. Brasília, 1999. Disponível em <http://www.planalto.gov.br/ccivil_03/leis/19795.htm>. Acesso em 07 mai. 2019.

BRILHA, José. Patrimônio Geológico e geoconservação: A conservação da natureza na sua vertente geológica. Palimage, 2005. 183 p.

BRILHA, José Bernardo Rodrigues. A Importância dos Geoparques no Ensino e Divulgação das Geociências. Geologia USP, São Paulo, v. 5, n. 1, p.27-33, out. 2009.

CARNEIRO, Celso dal Ré; TOLETO, Maria Cristina Mota; ALMEIDA, Fernando Flávio Marques de. Dez motivos para a inclusão de de Geologia na Educação Básica. Revista Brasileira de Geociências, São Paulo, v. 34, n. 4, p.553-560, dez. 2004.

CAVALCANTI, Marcelo José; MOREIRA, Enzo de Oliveira. Metodologia para estudo de caso. Palhoça: Unisulvirtual, 2007. 110 p.

FÉ, Marcelo Martins de Moura. Evolução Geomorfológica da Ibiapaba Setentrional, Ceará: Gênese, modelagem e conservação. 309 f. Tese (Doutorado) - Curso de Geografia, Universidade Federal do Ceará, Fortaleza, 2015.

FÉ, Marcelo Martins de Moura et al. Geoeducação: A educação ambiental aplicada na geoconservação. In: SEABRA, Giovanni. Educação Ambiental e Biogeografia. Ituiutaba: Barlavento, 2016. p. 829-842. 
GODOY, Michel Marques; BINOTTO, Raquel Barros; WILDNER, Wilson. Geoparque Caminho dos Cânions do Sul (RS/SC): Proposta. Porto Alegre: CPRM, 2010. 36 p.

GONÇALVES, Teresinha Maria. Do conceito de espaço ao conceito de território. In: LADWIG, Nilzo Ivo; SCHAWALM, Hugo (Org.). Gestão socioambiental das cidades no século XXI: teorias, conflitos e desafios. Florianópolis: Insular, 2013. Cap. 5. p. 135-150.

MAMPITUBA, Prefeitura Municipal de. Localização. Disponível em: <http://www.mampituba.rs.gov.br/como-chegar/ > Acesso em 07 mai. 2019.

OLIVEIRA, José Carlos da Silva. Geoparques no Brasil: Foco geográfico na superação dos desafios. 2014. 108 f. Monografia (Especialização) - Curso de Geografia, Universidade de Brasília, Brasília, 2014.

RODRIGUES, Joana de Castro; CARVALHO, Carlos Neto de; CATANA, Maria Manuela. Módulo de Ensino de Geociências no campo: os Geoparques e Geossítios. Caetano Branco: Geoschools, 2013. 64 p.

ROSA, Tarcisio Roldão da; ROCHA, Isa de Oliveira; MARIMON, Maria Paula Casagrande. Considerações sobre a proposta de planejamento regional no Extremo Sul de Santa Catarina: Projeto Geoparque Caminho dos Cânions do Sul. Revista Brasileira de Planejamento e Desenvolvimento, Curitiba, v. 4, n. 2, p.148-167, dez. 2015.

SANTOS, Milton. Da totalidade ao lugar. 7.ed. São Paulo: Editora da Universidade de São Paulo, 2005.

SANTOS, Milton. Técnica, espaço e tempo: globalização e meio técnico científico informacional. 2. ed. São Paulo: Hucitec, 1994. 190 p.

TOMASI, Rodrigo von Mengden. Desenvolvimento regional sustentável com base no turismo: A proposta do Geoparque dos Canyons do Brasil. 2011. 115 f. Dissertação (Mestrado) - Curso de Administração, Universidade Federal do Rio Grande do Sul, Porto Alegre, 2011.

UNESCO. International Network of GEOPARKS. Disponível em: <

http://www.globalgeopark.org/UploadFiles/2012_9_6/GGN2010.pdf >. 2010. Acesso em 03 abr. 2019.

YIN, Robert K.. Estudo de caso: Planejamento e métodos. 2. ed. Rio de Janeiro: Bookman, 2001. $200 \mathrm{p}$. 